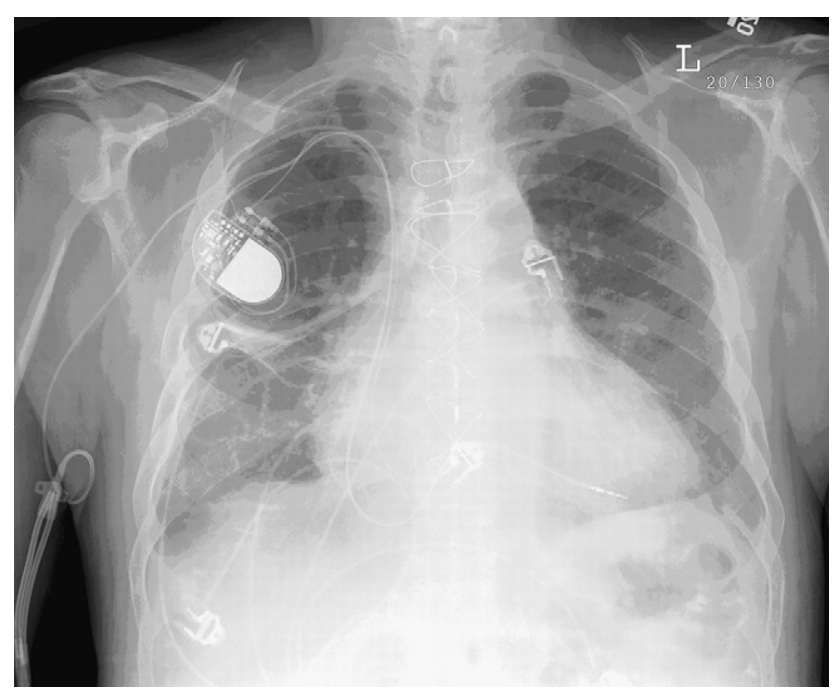

FIGURE 2. Discharge chest radiograph showing dual lead pacer in place. Pulmonary vasculature is normal. No edema, no pneumothorax. There are residual tiny pleural effusions on the right side.

At 28 months' follow-up, TTE and right heart catheterization revealed normal left ventricular size and function, EF $60 \%$; mild RV dilatation with mildly reduced RV systolic function; moderate regurgitation of the mitral and tricuspid valves, mean right atrial pressure of $4 \mathrm{~mm} \mathrm{Hg}$; and cardiac index $4.1 \mathrm{~L} \cdot \mathrm{min}^{-1} \cdot \mathrm{m}^{-2}$.

\section{DISCUSSION}

Registry data from the International Society of Heart and Lung Transplantation shows that despite advances in perioperative management, RV dysfunction is still a catastrophic event after heart transplantation. Indeed, it accounts for $50 \%$ of all cardiac complications in patients after heart transplantation and is associated with an early mortality of $19 \%{ }^{4}$

Early deaths due to RV dysfunction after cardiac transplantation are attributable to either an increase in pulmonary vascular resistance in the recipient or a loss of contractility in the donor heart. ${ }^{5}$ In this patient, it is likely that the combination of chronic pulmonary hypertension, moderate donor allograft left ventricular hypertrophy, and long cold ischemic time of the donor allograft contributed to perioperative RV dysfunction.

Chen and colleagues ${ }^{3}$ described their experience of temporary RV support, and the maximum support period time was 190 hours. The present case is unique in that the patient was successfully weaned from the RVAD after 53 days of support, and the recovered right ventricle is still functioning well more than 2 years postoperatively. To the best of our knowledge, this is the longest support to RV failure after heart transplantation. This case suggests that the RV failure following heart transplantation is reversible, and its recovery is possible beyond 50 days. We should consider the longterm use of the RVAD as an option in managing refractory primary graft failure following heart transplantation.

\section{References}

1. Stobierska-Dzierzek B, Awad H, Michler RE. The evolving management of acute right-sided heart failure in cardiac transplant recipients. J Am Coll Cardiol. 2001; 38:923-31.

2. Nakatani T, Radovancevic B, Frazier OH. Right heart assist for acute right ventricular failure after orthotopic heart transplantation. ASAIO Trans. 1987;33:695-8.

3. Chen JM, Levin HR, Rose EA, Addonizio LJ, Landry DW, Sistino JJ, et al. Experience with right ventricular assist devices for perioperative right-sided circulatory failure. Ann Thorac Surg. 1996;61:305-10.

4. Hosenpud JD, Bennett LE, Keck BM, Boucek MM, Novick RJ. The Registry of the International Society for Heart and Lung Transplantation: seventeenth official report-2000. J Heart Lung Transplant. 2000;19:909-31.

5. Kirklin JK, Naftel DC, Kirklin JW, Blackstone EH, White-Williams C, Bourge RC. Pulmonary vascular resistance and the risk of heart transplantation. J Heart Transplant. 1988;7:331-5.

\title{
Huge aneurysms of the aortic sinuses of Valsalva with leaflet perforation in an infant: A case report
}

\author{
Atsushi Kawaguchi, MD, Kenji Waki, MD, Yoshio Arakaki, MD, and Kiyoshi Baba, MD, Shizuoka, Japan
}

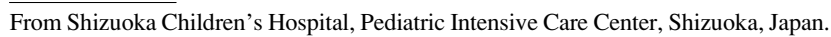
Disclosures: None.

Received for publication Dec 27, 2007; revisions received May 25, 2008; accepted for publication July 5, 2008; available ahead of print July 23, 2009.

Address for reprints: Shizuoka Children's Hospital, Pediatric Intensive Care Center, 860 Urushiyama, Aoi-ku, Szhiuoka-city, Shizuoka, 420-8660 Japan (E-mail: a-kawaguchi@sch.pref.shizuoka.jp).

J Thorac Cardiovasc Surg 2010;139:e54-6

$0022-5223 / \$ 36.00$

Copyright $\odot 2010$ by The American Association for Thoracic Surgery doi:10.1016/j.jtcvs.2008.07.068
Congenital aneurysm of the sinus of Valsalva (ASV) is a rare cardiovascular anomaly in infants. ASV usually affects only one aortic sinus and is silent until rupture occurs. Only a few cases of multiple ASV have been reported ${ }^{1-3}$ and cardiac failure resulting from aortic regurgitation in an infant with ruptured ASV is very uncommon. Here, we report the case of a 5-month-old male infant with ruptured multiple ASV and severe aortic regurgitation. 


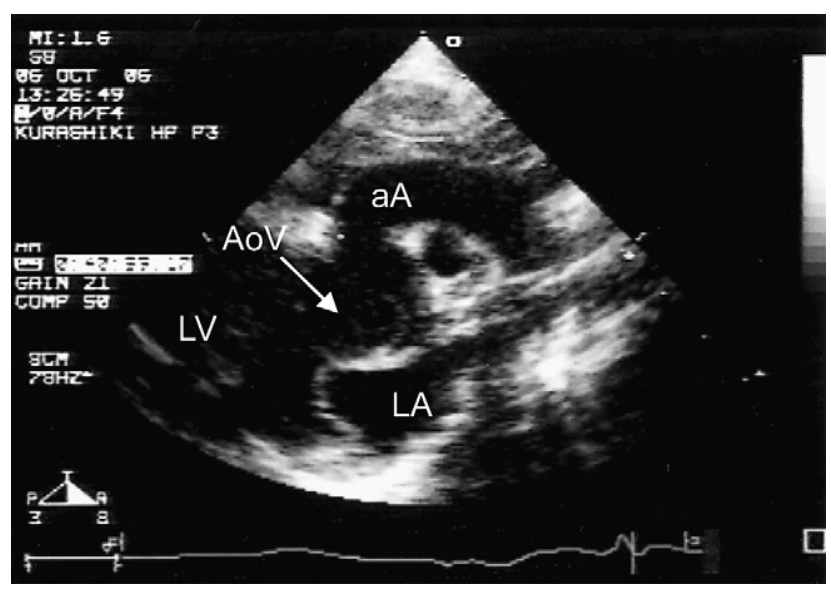

FIGURE 1. Transthoracic echocardiographic image showing an aortic valve $18.2 \mathrm{~mm}$ (200\% of normal) in diameter, unruptured and markedly dilated sinuses of Valsalva (largest diameter: $22.2 \mathrm{~mm}$ ), and a normally sized ascending aorta (diameter: $11.3 \mathrm{~mm}$ ). $L V$, Left ventricle; $L A$, left atrium; $A o V$, aortic valve; $a A$, ascending aorta.

\section{CLINICAL SUMMARY}

A 5-month-old male infant was referred to our institute for evaluation of a heart murmur. There was no family history of congenital heart disease, and the patient had no signs of growth failure and no history of infection. His vital signs were within normal limits, his appearance was good, and he had no clinical characteristics of Marfan or Ehlers-Danlos syndrome. Auscultation of the chest revealed an ejection click, a grade 2/6 systolic murmur in the second left intercostal space, and no apparent diastolic murmur. A chest X-ray film showed a slightly enlarged heart (cardiothoracic ratio: $55 \%$ ) and slight lung congestion, but electrocardiographic findings were within normal limits. Initial echocardiographic and Doppler examinations revealed left ventricular dilatation (left ventricular dimension diastole: $32.9 \mathrm{~mm}, 133 \%$ of the normal value), a $61 \%$ ejection fraction, mild aortic regurgitation and mitral regurgitation, a dilated aortic valve (diameter: $18.2 \mathrm{~mm}, 200 \%$ of the normal diameter), aneurysms of the left and noncoronary sinuses of Valsalva (largest diameter: $22.2 \mathrm{~mm}$ ), and a normally sized ascending aorta (diameter: $11.3 \mathrm{~mm}$ ) (Figure 1). There was no sign of a perforated ASV at that time. Results from 64-multislice computed tomography supported the echocardiographic findings (Figure 2). We decided to observe the infant as an outpatient because his symptoms were mild.

Two days later, the infant was brought back to our hospital because of poor feeding, a sickly complexion, and tachypnea. Blood pressure was $100 / 45 \mathrm{~mm} \mathrm{Hg}$, pulse rate was 170 beats/min, and the pulses were bounding. The infant looked pale and was in severe respiratory distress. A chest x-ray film showed that lung congestion had progressed and echocardiographic findings showed a markedly dilated left ventricle and severe aortic regurgitation. The infant also had a negative blood culture and tests were negative

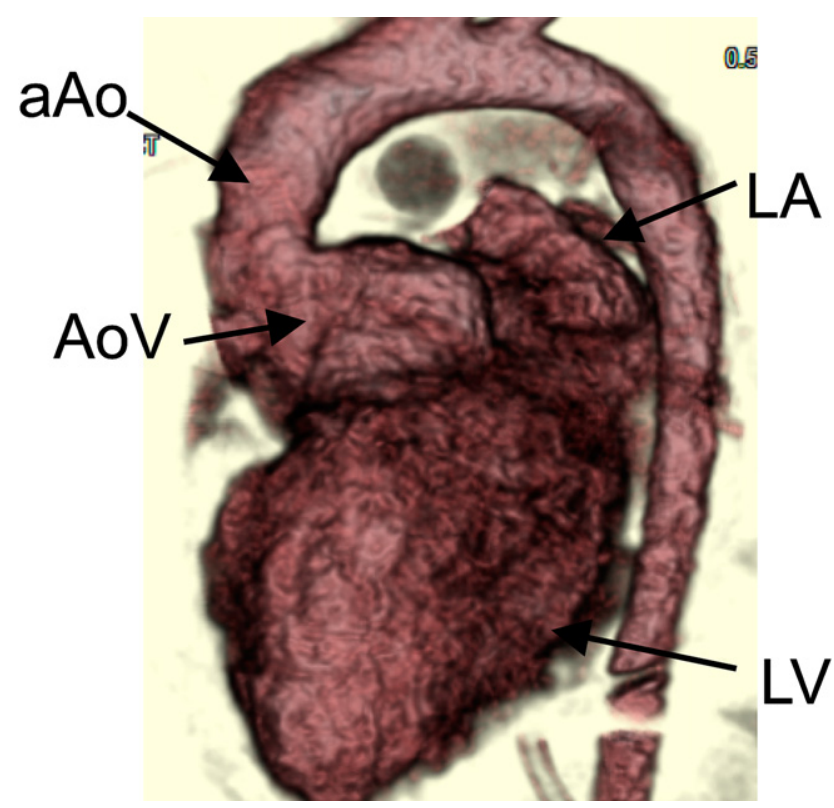

FIGURE 2. Three-dimensional computed tomogram showed markedly dilated, huge sinuses of Valsalva. For abbreviations, see Figure 1.

for inflammatory markers. The patient was intubated in the intensive care unit and urgent surgery was performed on day 3 after admission. Surgical findings included perforation of the leaflet in the bottom area of the noncoronary cusp and unbalanced leaflets with a small right coronary cusp and prolapsed left coronary and noncoronary cusps (we define the state of perforation as rupture). Dilated sinuses of Valsalva were closed and covered with pericardial patches. The aortic valves were repaired by valvuloplasty with plication of the noncoronary and left coronary cusps, including the perforation site, using treated pericardium (Figure 3 ). The postoperative course was good and the patient was discharged on postoperative day 50 .
A

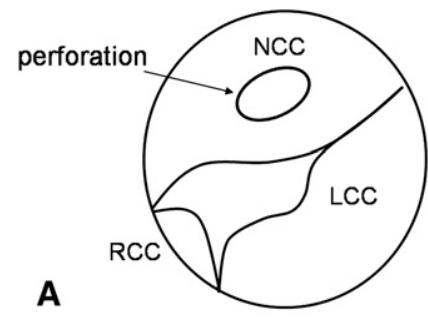

B

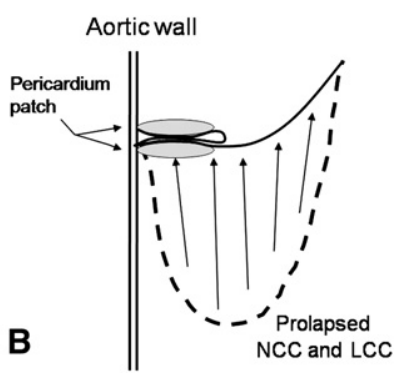

FIGURE 3. Diagram of aortic valve repair. A, Perforation of the leaflet in the bottom area of the NCC, unbalanced leaflets with a small RCC, and prolapsed LCC and NCC. B, Elongated free margin of leaflets were sutured at commissure to maintain correct leaflet length and sandwiched against aortic wall by pericardial patches. $N C C$, Noncoronary cusp; $R C C$, right coronary cusp; $L C C$, left coronary cusp. 


\section{DISCUSSION}

ASV is a very uncommon cardiac malformation in infants. A congenital weakness at the junction of the aortic media and the annulus fibrosis is considered to be the cause of congenital ASV, but the pathogenesis is not completely understood. ASV usually affects only one aortic sinus, and only a few cases of multiple ASV have been reported. ${ }^{1-3}$ ASV is found most often in the right coronary sinus, less often in the noncoronary sinus, and least often in the left coronary sinus. ${ }^{4}$ Most patients with unruptured ASV are asymptomatic and the condition is usually detected only incidentally. Congenital ASV is commonly found owing to rupture by infection, trauma, or degenerative disease and is often concomitant with other congenital defects, especially ventricular septal defect. Ruptured ASV is usually identified after symptoms such as heart failure and vascular obstruction. ${ }^{4}$ Our patient had aneurysms of the noncoronary and left coronary aortic sinuses of Valsalva, but no concomitant cardiac malformation, suggesting that his may be an extremely uncommon case. ${ }^{5,6}$

A prolapsed valve that causes aortic regurgitation is found in at least $10 \%$ of patients with ASV. The prolapse occurs when the ASV involves the aortic annulus, when ventricular sseptal defect is concomitant and removes the support of the conus arteriosus, or when a Venturi effect pulls the aortic cusp of the sinus of Valsalva into the right ventricular cavity in a patient with a ventricular septal defect. ${ }^{4}$ As described above, prolapsed aortic valves were identified in the initial examination of our patient, but the cause of rapid progression of aortic regurgitation remains unclear. Sudden perforation (rupture) may have affected his clinical course. This case suggests that it is important to recognize that acute left heart failure can progress with exacerbated aortic regurgitation via an unknown pathophysiologic mechanism, even if the sinus is not ruptured and the patient is not in bad condition, and that such cases may require urgent surgical repair.

\section{References}

1. Pomerance A, Davis MJ. Congenital aneurysms of all three sinuses of Valsalva. J Pathol. 1965;89:607-10.

2. Hassan C-P, Carolyn M, Ross M. Echocardiographic diagnosis of multiple congenital aneurysm of the sinus of Valsalva. Br Heart J. 1988;59:724-6.

3. Simic O, Schneider B, Stein J. Unruptured aneurysms of the non-coronary and left sinuses of Valsalva accompanied by severe aortic regurgitation. Eur J Cardiothorac Surg. 1996;10:1030-2.

4. Ott DA. Aneurysm of the sinus of Valsalva. Semin Thorac Cardiovasc Surg Pediatr Card Surg Annu. 2006;9:165-76.

5. Bastos P, Sousa A, Areias C. Congenital aneurysm of the sinus of the Valsalva. Surgical repair in an infant. Thorac Cardiovasc Surg. 1985;33:125-7.

6. Breviere GM, Vaksmann G, Francart C. Ruptured of sinus of Valsalva aneurysm in neonate. Eur J Pediatr. 1990;149:603-4. 